\title{
Comparative Assessment of Different Dissolution Apparatus for Floating Drug Delivery Systems
}

\author{
Atul D. Karande ${ }^{1}$, Pramod G. Yeole $e^{1,2}$
}

\begin{abstract}
The aim of this study was to evaluate and compare the different official and unofficial dissolution apparatus proposed for floating drug delivery systems. Establishment of in vitro dissolution and in vivo performance (IVIVR), and quality control of solid oral dosage forms depends mainly upon dissolution testing. This study is an investigation of the effect of modifications in dissolution conditions on the floating drug delivery system. The floating drug delivery systems were evaluated by placing them in the dissolution apparatus in accordance with the USP type 2 (paddle) method, placing them in a helical wire sinker (USP recommended) below the designed mesh device for achieving full surface exposure to the dissolution medium, and subjecting them to the dissolution in a modified dissolution apparatus. Results indicate that the overall release profiles from floating drug delivery systems of cefuroxime axetil are sensitive to their positioning in the dissolution apparatus. This was attributed to the relative insolubility of the cefuroxime axetil in water, as different positioning intensifies the erosional and diffussional dissolution forces applied to dosage forms and facilitates maintenance of the sink condition. Statistical analysis of the data was performed by comparing the $t_{30 \%}, t_{50 \%}$, and $t_{80 \%}$ and by similarity factor assessment. The overall results show that the modified method provides a more reproducible dissolution profile, eliminates the risk of floating dosage forms adhering to the paddles, and simplifies the sampling procedure by producing a smaller volume of dissolution medium. The modified dissolution apparatus can be more rationally accepted as a substitute for the in vivo dissolution assessment of the tablet dosage form as it more closely simulates most of the in vivo conditions, for example, erosional and diffussional forces and normal Gl conditions like gastric volume, acid secretion rate, and so on.
\end{abstract}

\section{INTRODUCTION}

D issolution testing is an in vitro technique of great importance in formulation and development of pharmaceutical dosage forms, as it can be used as a substitute for in vivo studies under strictly defined and specified conditions (1). For the comparison of in vitro dissolution data and for use of such data for in vivo bioequivalence testing and in vitro-in vivo correlations (IVIVC) (1), dissolution testing should be carried out under physicochemically and hydrodynamically defined conditions so that results obtained are accurate and reproducible.

New modified release formulation technologies and diversity in dosage form design necessitate the development of new procedures or appropriate modification of the existing apparatus to test alternative dosage forms such as a swellable, floatable drug delivery system $(2,8)$. Traditionally, floating dosage forms were evaluated with the aid of USP type 2 (paddle) apparatus (3), which is associated with a number of shortcomings and drawbacks such as adherence of dosage form to the paddle shaft or sample withdrawal aids (pipette), incomplete exposure to the dissolution medium, and failure to mimic in vivo conditions. Literature study has revealed that in order to overcome these drawbacks and shortcomings, researchers have modified the conventional dissolution method and proposed different modified dissolution apparatus (3-6).
This study aims to evaluate positioning of the drug delivery system within the dissolution apparatus over the drug release, which was studied with the aid of four different dissolution apparatus:

A: USP type 2 apparatus

B: USP type 2 (wire helix) apparatus (USP recommended)

C: USP type 2 (mesh designed) apparatus and

D: Modified dissolution apparatus.

\begin{tabular}{l}
\hline Table 1: Formulation of Floating Matrix tablet \\
\begin{tabular}{|lc|}
\hline Ingredients & Quantity per Tablet (mg) \\
\hline Drug & 300 \\
\hline HPMC & 90 \\
\hline Mannitol & 40 \\
\hline Citric acid & 20 \\
\hline NaHCO & 50 \\
\hline Mag. stearate & 5 \\
\hline Total & 505 \\
\hline
\end{tabular}
\end{tabular}

\footnotetext{
${ }^{1}$ Department of Pharmaceutics, Institute of Pharmaceutical Education and Research, Borgaon (Meghe), Hinghanghat Road, Wardha, 442 001,

Maharashtra, India
}

\section{${ }^{2}$ Corresponding Author}


Table 2: Comparative construction features of different dissolution apparatus

\begin{tabular}{|lllll|}
\hline Specifications & $\begin{array}{l}\text { USP type 2 } \\
\text { (Paddle) }\end{array}$ & $\begin{array}{l}\text { USP type 2 } \\
\text { (Wire helix) }\end{array}$ & $\begin{array}{l}\text { USP type 2 } \\
\text { (Mesh designed) }\end{array}$ & Modified \\
\hline $\begin{array}{l}\text { Volume of } \\
\text { dissolution medium }\end{array}$ & $900 \mathrm{~mL}$ & $900 \mathrm{~mL}$ & $900 \mathrm{~mL}$ & $70 \mathrm{~mL}$ \\
\hline $\begin{array}{l}\text { Rate of } \\
\text { agitation }\end{array}$ & $55 \mathrm{rpm}$ & $55 \mathrm{rpm}$ & $55 \mathrm{rpm}$ & $\begin{array}{l}55 \mathrm{rpm} \\
\text { (Magnetic stirrer) }\end{array}$ \\
\hline Paddle position & Normal & Normal & $\begin{array}{l}\text { Raised from normal } 77 \mathrm{~mm} \text { from } \\
\text { bottom of vessel }\end{array}$ & $\begin{array}{l}\text { Magnetic stirrer was used instead } \\
\text { of paddle and placed at bottom }\end{array}$ \\
\hline Modifications & No & $\begin{array}{l}\text { Wire helix is wound } \\
\text { around the dosage form }\end{array}$ & $\begin{array}{l}\text { Wire mesh is placed at 72 mm } \\
\text { height from bottom of vessel } \\
\text { below which dosage form is placed }\end{array}$ & $\begin{array}{l}\text { Sink condition maintenance by } \\
\text { flow through arrangement }\end{array}$ \\
\hline
\end{tabular}

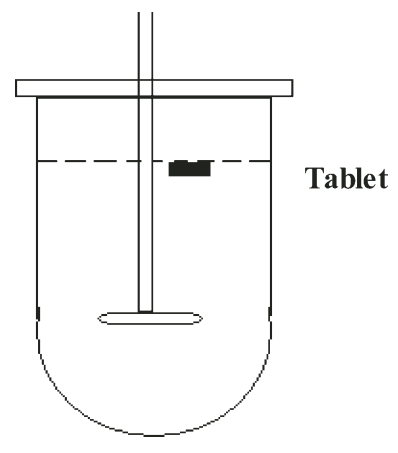

Figure 1A: Schematic presentation of the USP type 2 apparatus

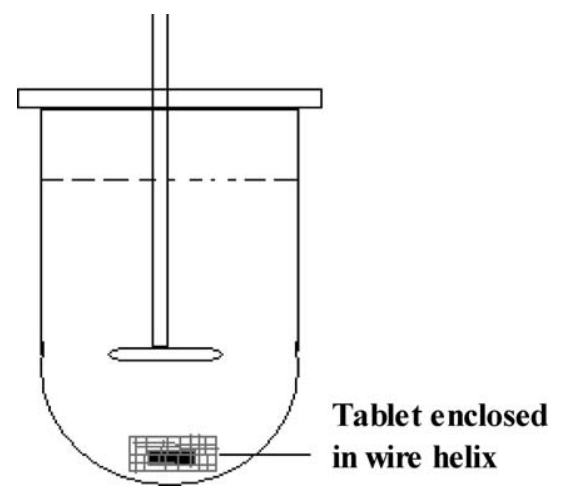

Figure 1B: Schematic presentation of the USP type 2 (Wire helix) apparatus

For Apparatus B, a helical wire sinker ("wire helix") was wound around the delivery system, and in Apparatus C, the mesh designed apparatus (Burns et al.), the delivery system was placed below the mesh. (Fixed at a height of 72 $\mathrm{mm}$ from the bottom of the vessel, the paddle position was raised from its normal, i.e., 77-mm, position.) The modified dissolution apparatus delivery system (I) was subjected to conditions similar to those experienced in the Gl tract: gastric volume of $70 \mathrm{~mL}$, gastric emptying and gastric secretion rates of $2 \mathrm{~mL} / \mathrm{min}$.

This study considers the time taken for $X \%$ drug release $\left(t_{x \%}\right)$ and similarity factor " $f_{2}$ "as a tool for dissolution data interpretation under different hydrodynamic conditions for dissolution behavior of a swellable floatable drug delivery system $(7,9-12)$.

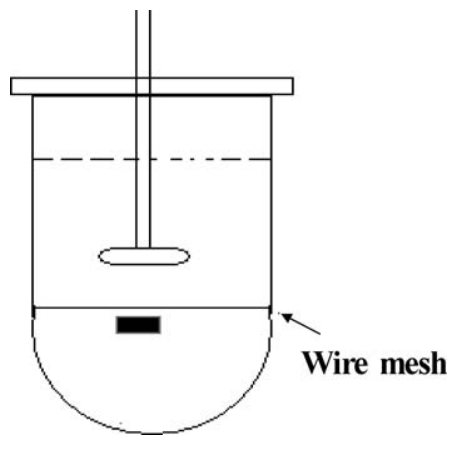

Figure 1C: Schematic presentation of the USP type 2 (Mesh designed) apparatus

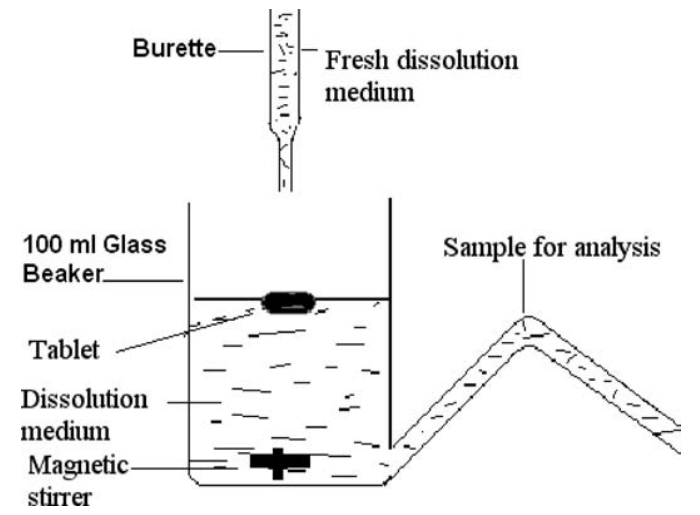

Figure 1D: Schematic presentation of the Modified Dissolution apparatus

\section{MATERIALS AND METHODS}

Cefuroxime axetil was obtained from Aristo Pharmaceuticals Ltd., India; hydroxypropylmethylcellulose (HPMC K4M) was obtained from DOW Chemical Co., USA. Mannitol, citric acid (anhydrous), and $\mathrm{NaHCO}_{3}$ were obtained from MERCK India Ltd., India. All other ingredients used were of analytical grade and used as provided.

\section{Formulation of floating matrix tablet}

Hydrophilic swellable matrix tablets were prepared by direct compression technique using a flat-face punch on a single-stroke machine. Table 1 depicts the actual quantities of ingredients used for each tablet formulation.

The physical properties of the tablets were acceptable and 
well within the specified limits set by the USP. Content uniformity for drug was similar for all the batches (100 $\pm 3 \%)$.

\section{Dissolution study of cefuroxime axetil tablet}

The features of different dissolution apparatus used in this study are summarized in Table 2 (2-6).

The dissolution study of cefuroxime axetil tablet was carried out according to the monograph given in USP.

Nine hundred $\mathrm{mL}$ of $0.07 \mathrm{~N} \mathrm{HCl}$ was filled in a dissolution apparatus and the temperature of the medium was set at $37 \pm 0.5^{\circ} \mathrm{C}$. One tablet was placed in each dissolution vessel, and the paddle rotational speed was set at $55 \mathrm{rpm}$ (USP Specified conditions). The $10 \mathrm{~mL}$ of sample was withdrawn at predetermined time intervals over $12 \mathrm{hr}$ with replacement (fresh medium). All samples were filtered through a $0.5-\mathrm{mm}$ filter paper. The samples were analyzed for drug content against $0.07 \mathrm{~N} \mathrm{HCl}$ as a blank, at $278 \mathrm{~nm}$ using a double-beam UV spectrophotometer. The content of the drug was calculated using an equation obtained from the standard curve. The percentage cumulative drug release was calculated (procedure adopted for USP type 2; helical wire sinker, and Burns apparatus). Modifications in the apparatus are illustrated in Table 2 and in Figure 1 $(\mathrm{A}-\mathrm{C})$.

The modified dissolution apparatus was created by attaching an S-shaped side arm (glass tube), capable of holding $70 \mathrm{~mL}$ of dissolution medium $(0.07 \mathrm{~N} \mathrm{HCl})$, to a 100 $\mathrm{mL}$ glass beaker. The medium was stirred by a magnetic stirrer. A burette was mounted above the beaker to deliver the dissolution medium at a flow rate of $2 \mathrm{~mL} / \mathrm{min}$ (Figure 1D). The tablet was put in the modified beaker containing 70 $\mathrm{mL}$ of dissolution medium (after flotation of the tablet); the medium was stirred at $55 \mathrm{rpm}$. The temperature of the medium was maintained at $37 \pm 0.5^{\circ} \mathrm{C}$. From the burette, $0.07 \mathrm{~N} \mathrm{HCl}$ was added at the rate of $2 \mathrm{~mL} / \mathrm{min}$. Samples of 10 $\mathrm{mL}$ were collected at predetermined time intervals for $12 \mathrm{hr}$. All the samples were filtered through a $0.5-\mathrm{mm}$ filter paper. The percentage drug release was calculated as described above. All the studies were carried out in triplicate, $\mathrm{n}=3$.

\section{Treatment of dissolution data}

Dissolution data obtained were subjected to a time point analysis, $x \%$ release at time $t$ and to a similarity factor assess-

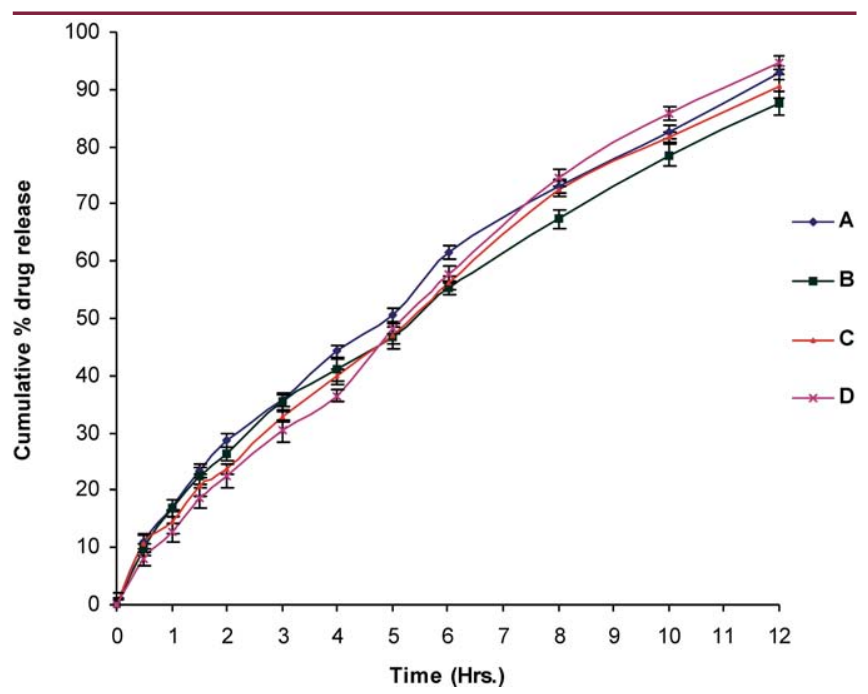

Figure 2: Comparative release profile of cefuroxime axetil release from floating tablet. $(n=3)$. A: USP type 2 apparatus; $B$ : USP type 2 (Wire helix) apparatus; C: USP type 2 (Mesh designed) apparatus; D: Modified dissolution apparatus

ment. In the time point analysis, $t_{30 \%}, t_{50 \%}$, and $t_{80 \%}$ were calculated from the overall dissolution profile. The $t_{80 \%}$ values thus obtained were analyzed by one-way analysis of variance (ANOVA) followed by Dunnet $t$-test. The results were expressed as mean \pm standard deviation and $p<0.05$ was considered as significant.

Guidelines and specific published works on extended release solid oral dosage forms describe the mathematical treatment of dissolution data by comparing dissolution profiles using the similarity factor $f_{2}$, which is defined as follows:

$$
f_{2}=50 \log \left\{\left[1+\frac{1}{n} \sum_{t=1}^{n} w_{t}\left(R_{t}-T_{t}\right)^{2}\right]^{-0.5} \times 100\right\}
$$

where $n$ is the number of pull points, $w_{t}$ is the optional weight factor, and $R_{t}$ is the reference assay at time point $t$.

In this study, the reference and test products are identical; the product was evaluated using the standard USP type 2 (paddle) as a reference, and the USP type 2 (wire helix), USP type 2 (mesh designed), and modified dissolution apparatus as the test apparatus. The $f_{2}$ value between 50 and 100

Table 3: Treatment of Dissolution Data

\begin{tabular}{|c|c|c|c|c|}
\hline \multirow{2}{*}{ Parameter } & \multicolumn{4}{|c|}{ Dissolution Apparatus } \\
\cline { 2 - 5 } & USP type 2 & USP type 2 (Wire helix) & USP type2 (Mesh designed) & Modified \\
\hline$t_{30 \%}$ & $2.4 \pm 0.264$ & $2.6 \pm 0.132$ & $2.8 \pm 0.05$ & $3.0 \pm 0.20$ \\
\hline$t_{50 \%}$ & $5.0 \pm 0.15$ & $5.6 \pm 0.25$ & $5.4 \pm 0.20$ & $5.2 \pm 0.15$ \\
\hline$t_{80 \%}$ & $9.3 \pm 0.20$ & $10.6 \pm 0.30^{* *}$ & $9.6 \pm 0.10^{*}$ & $9.0 \pm 0.20^{*}$ \\
\hline$f_{2}$ value & Reference & 61.22 & 77.25 & 75.25 \\
\hline $\begin{array}{l}t_{X \%} \text { values indicates time in minutes } \\
*\end{array}>0.05,{ }^{* *} p<0.01$ when compared with reference. Each value represents the mean \pm standard deviation $(n=3)$
\end{tabular}


suggests the test and reference profiles are identical, and as the value becomes smaller, the dissimilarity between the release profiles increases.

\section{RESULTS AND DISCUSSION}

The respective dissolution profiles are shown in Figure 2. The dissolution profiles for cefuroxime axetil demonstrate that the overall release trends from the swellable floatable system are sensitive both to their position in the apparatus and also to the hydrodynamic conditions.

Application of the helical wire sinker to the swellable floatable cefuroxime axetil delivery system appeared to inhibit the three-dimensional swelling process of the dosage form and consequently suppressed the drug release from the formulation.

However, drug release was faster when the floatable delivery system was placed under mesh. In the modified apparatus, initially slow drug release occurred, but after 4-5 hours, the release rate increased and showed the smallest $t_{80 \%}$ (Table 3). The $t_{80 \%}$ value for the floatable system in the modified dissolution apparatus is the lowest value obtained. The cause of such a low $t$ value can be attributed to floatation, to greater erosion of the delivery system, and to the maintenance of the sink condition, as there occurs continuous fluid flow through the apparatus (for instance, as $2 \mathrm{~mL}$ of fresh medium is introduced, the same volume of analyte, the dissolution fluid, leaves the apparatus) as illustrated in Figure 1D.

The statistical analysis of $t_{80 \%}$ values indicates that there is no significant difference between USP type 2 apparatus with paddle, modified, and mesh designed ( $p>0.05$ ). However, a significant difference was observed with the USP type 2 apparatus with the wire helix $(p<0.001)$. These findings might be due to the greater floatation and mechanical attrition of the USP type 2 apparatus or to erosion of the delivery system; the floatable system tends to consistently adhere to and detach itself from the paddle shaft and to constantly rotate around the paddle shaft during the entire dissolution period. In the mesh designed apparatus, the erosional forces were more intense as the wire mesh continuously abraded the tablet. This resulted in significant visible matrix erosion and particle separation; consequently, release rate was faster.

\section{CONCLUSION}

Overall, this study concludes that, for the floatable system containing cefuroxime axetil, full surface exposure and maintenance of sink condition by flow-through techniques resulted in release profiles that are rationally more acceptable. In this investigation with modified dissolution apparatus, in vivo conditions are mimicked, including gastric acid secretion rate, gastric volume, and gastric emptying, and the merits of the apparatus are minimization of dissolution fluid volume and elimination of the risk of tablet adherence to the apparatus walls, agitation device, and sampling aid (pipette).

Finally, the determination of an accurate and reproducible dissolution profile is achievable when full surface exposure and maintenance of sink condition are taken into consideration using the modified dissolution apparatus. Thus, from the overall study, it can be concluded that the modified dissolution apparatus is the most promising method and can be adopted for the routine quality control test or for IVIVC purposes due to its simplicity and greater flexibility in assessing the overall similarity of dissolution profiles which are so often required during product modification and IND/ANDA revisions.

\section{ACKNOWLEDGEMENT}

The authors would like to thank the All India Council for Technical Education, New Delhi, India, for providing Predoctoral fellowship and Aristo Pharmaceuticals Ltd. India for providing gratis sample of cefuroxime axetil.

\section{REFERENCES}

1. Williams, R. L.; Upton, R. A.; Ball, L.; Barun, E. T.; Lesson, L. J. Development of new control release formulation of chlorpheniramine maleate using in-vitro, in-vivo correlation. J. Pharm. Sci. 1995, 80 (1), 22-25.

2. Despande, A. A.; Rhodes, C. T.; Shah, N. H.; Malick, A. W. Controlled release drug delivery system for prolonged gastric residence: an overview. Drug Dev. Ind. Pharm. 1996, 22, 531-539.

3. The United States Pharmacopoeia 24, Asian Ed.; United States Pharmacopeial Convention, Inc: Rockville, MD, 2000; pp 1941-1943.

4. Burns, S. J.; Attwood, D.; Barnwell, S. G. Assessment of a dissolution vessel designed for floating and erodible dosage forms. Int. J. Pharm. 1998, 160, 213-218.

5. Durig, T. Evaluation of Floating and Sticking extended release delivery systems: an unconventional dissolution test. J. Controlled Release 2000,67, 37-44.

6. Gohel, M. C.; Mehta, P. R.; Dave, R. K.; Bariya, N. H. A more relevant dissolution method for evaluation of floating drug delivery system. Dissolution Technologies 2004, 11 (4), 22-25.

7. Hilton, A. K.; Deasy, P. B. In vitro and in vivo evaluation of an oral sustained- release floating dosage form of amoxicillin trihydrate. Int. J. Pharm. 1992, 86, 79-88.

8. Rohrs, B. R. Dissolution method development for poorly soluble compounds. Dissolution Technologies 2001, $8(3), 6-12$.

9. Dave, B. S.; Avani, F.A.; Patel, M. M. Gastroretentive drug delivery system of ranitidine hydrochloride: Formulation and in vitro evaluation. AAPS PharmSciTech 2004, 5 (2), 1-6.

10. Yang, L.; Eshraghi, J.; Fassihi, R. A new intragastric delivery system for the treatment of Helicobacter pylori associated gastric ulcer: in vitro evaluation. J. Controlled Release 1999, 57, 215-222.

11. Costa, P. An alternative method to the evaluation of similarity factor in dissolution testing. Int. J. Pharm. 2001, 220, 77-53. 